\title{
Should we stay or should we go now? What happens to small mammals when grass is mown, and the implications for birds of prey
}

\author{
Claudia M. Garratt*, Jeroen Minderman \& Mark J. Whittingham
}

\begin{abstract}
School of Biology, Newcastle University, Newcastle upon Tyne, NE1 7RU, UK (corresponding author's e-mail: c.m.garratt@ncl.ac.uk)
\end{abstract}

Received 18 May 2011, final version received 29 Nov. 2011, accepted 2 Dec. 2011

Garratt, C. G., Minderman, J. \& Whittingham, M. J. 2012: Should we stay or should we go now? What happens to small mammals when grass is mown, and the implications for birds of prey. Ann. Zool. Fennici 49: 113-122.

With some raptors showing widespread declines, management of grassland to enhance access to their small mammal prey may be an important conservation tool. Many small mammal species prefer long grass as a habitat that offers protection from predation, and past studies on the consequences of grass cutting to small mammals have yielded mixed results. Using live trapping, we show that although mowing grass causes a rapid decline in small mammal captures, a small proportion of captures $(20 \%-27 \%)$ still occurred in patches of mown grass immediately after cutting. This proportion more than halved again when the cut grass that was initially left in situ was removed. We conclude that some small mammals may remain in mown areas provided some form of cover - i.e. the cut grass - is present. These findings are discussed in light of agrienvironment scheme options (e.g. grass margins) that could be improved to benefit birds of prey.

\section{Introduction}

Agriculture is the largest driver of extinction risk in birds (Green et al. 2005). European agri-environment schemes (AES) are designed, in part, to benefit biodiversity on farms (Kleijn et al. 2006, Whittingham 2007) and have existed since 1987 in England (Ovenden et al. 1998). Some AESs have substantially benefitted target species (e.g. Aebischer et al. 2000, Peach et al. 2001, Albrecht et al. 2007, Perkins et al. 2011) while others have shown no demonstrable benefit to target species or overall biodiversity (e.g. Kleijn et al. 2001, Kleijn et al. 2004, Davey et al. 2010).
Recent work suggested that adaptive management, or 'learning through doing' (Convention on Biological Diversity 2004), is a key tool to improve the biodiversity benefits from AESs (Perkins et al. 2011) by encouraging modification of AESs to improve their benefit for wildlife as new information comes to light.

Within the English AESs, grass margins have proven to be one of the most popular management options (Davey et al. 2010) and this has led to an increase of ca. 62000 ha in the area of grassland on farms in England since the mid1980s (Grice et al. 2007, Garratt et al. 2011). If wide and densely vegetated, grass margins 
should enhance numbers of small mammals on arable farmland (Shore et al. 2005, Aschwanden et al. 2007), a key resource for many birds of prey (Cavé 1968, Glue 1974, Korpimäki 1984, Village 1990, Korpimäki \& Norrdahl 1991, Redpath \& Thirgood 1999, Koks et al. 2007). However, in the UK some farmland specialist raptors such as the barn owl Tyto alba and the kestrel Falco tinnunculus are still declining (Risely et al. 2010, Garratt et al. 2011). These continued declines may indicate that the quality of grass margins in AESs can be improved to further benefit raptors that rely on small mammals. In this study, we wished to explore possibilities for doing this.

Previous work has shown that kestrels foraging on farmland prefer short grass above all other habitats available to them (Ashwanden et al. 2005, Whittingham \& Devereux 2008, Garratt et al. 2011), presumably as it increases accessibility to their prey. The same association has also been shown for other raptors (Baker \& Brooks 1981, Aschwanden et al. 2005). Thus the value of grassland to foraging raptors may be determined to a large extent by the length of the vegetation, suggesting that cutting or mowing could represent a beneficial management option. However, while cutting grass may improve access to small mammal prey for raptors, evidence suggests that small mammals prefer longer, dense grass or more densely vegetated habitats generally. Evidence exists of such associations for a range of species: e.g. field voles Microtus spp. (Birney et al. 1976, Hansson 1977, Bellamy et al. 2000, Tattersall et al. 2000), bank voles Myodes glareolus (formerly Clethrionomys glareolus) (Kikkawa 1964, Dickman \& Doncaster 1987, Shore et al. 2005, Butet et al. 2006) and common shrews Sorex araneus (Dickman \& Doncaster 1987, Butet et al. 2006, Aschwanden et al. 2007), although this association is less strong for shrews which are fairly ubiquitous (Churchfield et al. 1997). Some studies suggest that grass which is mown regularly probably only provides a temporary small mammal habitat (Lemen \& Clausen 1984, Sheffield et al. 2001, Edge et al. 1995). However, other studies suggest either that small mammals are not strongly affected by mowing (e.g. Jacob 2003, Jacob \& Hempel 2003) or that some subdominant indi- viduals remain in the cut grass (Meunier et al. 1999, Jacob \& Brown 2000).

Thus, in spite of previous work on the subject, the effect of cutting grass on the distribution of small mammals remains unclear. Clearly, the value of cutting or mowing of grassland as a management tool to benefit foraging raptors depends on fully understanding its effect on small mammals. In this paper, we present the results of a field experiment in which we manipulate the height of grass patches by cutting. Using live trapping, we test both the temporal and spatial effect of cutting on small mammal distribution. Ultimately we aim to provide recommendations for the management of grassland to improve habitat suitability for declining raptor species that rely on small mammals.

\section{Material and methods}

\section{Study site}

The experimental plots were located in a grassland nature reserve in northeast England $\left(54^{\circ} 49^{\prime} 52.7^{\prime \prime} \mathrm{N}, 1^{\circ} 29^{\prime} 44^{\prime \prime} \mathrm{W}\right)$. The reserve primarily consists of immature, artificial grassland on the site of a former opencast coal mine, containing areas of newly reseeded grassland and woodland consisting of immature native tree species planted from 1996 onwards. The grassland is dominated by ryegrass Lolium spp., and wildflowers such as clover Trifolium spp., vetches Vicia spp., bird's foot trefoil Lotus corniculatus and yellow rattle Rhinanthus minor.

Five experimental plots were established within the site; the closest two were $10 \mathrm{~m}$ apart and separated by a tarmac path and a ditch, the others were all separated by a minimum of $93.6 \mathrm{~m}$. Three of the experimental plots were small, fenced, managed meadows (two were cattle grazed over winter, and one was cut each year for hay). The other two were in an unfenced area of rough grassland which had undergone no management for the previous five years, and had only been cut once since being established in 1997. Mean experimental plot width was $36.96 \mathrm{~m}$ (range: $30.4-45.2 \mathrm{~m}$ ) and mean length $73.61 \mathrm{~m}$ (range: $40-121.25 \mathrm{~m}$ ). 


\section{Trapping protocol}

Trapping was carried out over nine days in August 2009. Sward height in both the precut/ control patches and treatment patches post-cutting was established by choosing ten random locations per plot and obtaining vegetation height using a tape measure. Mean vegetation height in the experimental plots prior to treatment was $68.3 \mathrm{~cm}$ (range: $31-114.1 \mathrm{~cm}$ ). Each experimental plot was divided in half, ensuring as far as possible that it was divided in such a way as to make the two halves equivalent in terms of surrounding habitat, and each half was randomly assigned as treatment (to be cut) or control (to be left long), by tossing a coin.

Trap-lines were placed a third of the way between the centre line and the boundary in either direction. Traps were spaced evenly along the trap line (ca. 4-7 $\mathrm{m}$ apart, varying with the size of the plot), with the first one being the same distance from the boundary fence as it was from the next trap (Fig. 1). Fifty Longworth small mammal traps were put out for each trapping session - ten traps per experimental plot - five in the treatment half, and five in the control. Traps contained hay as bedding, wild bird seed mix and dried mealworms as bait, and carrot as a source of moisture. All traps were set at a sensitivity of $4 \mathrm{~g}$. Trapping took place in four sessions before and after experimental grass cutting (Fig. 2). Each trapping session consisted of four rounds of trap checks at five hourly intervals:

Session 1: pre-cutting. The traps were placed out at 10:00, with the first check at 15:00, and were then checked through the night (at 20:00 and 01:00) before being checked and disarmed at 06:00 the following morning. Immediately following the first trapping session the traps were removed and the grass in the treatment halves of the experimental plots was cut to a mean height of $9.3 \mathrm{~cm}$ (range: $3.9-14.8 \mathrm{~cm}$ ) using tractor-towed agricultural mowing machinery. The traps were replaced empty and locked in their original positions immediately following cutting. The cut grass was left in situ and used as cover for the traps in all but one of the plots (plot 4, see below).

Session 2: $20 \mathrm{~h}$ after cutting. The traps were

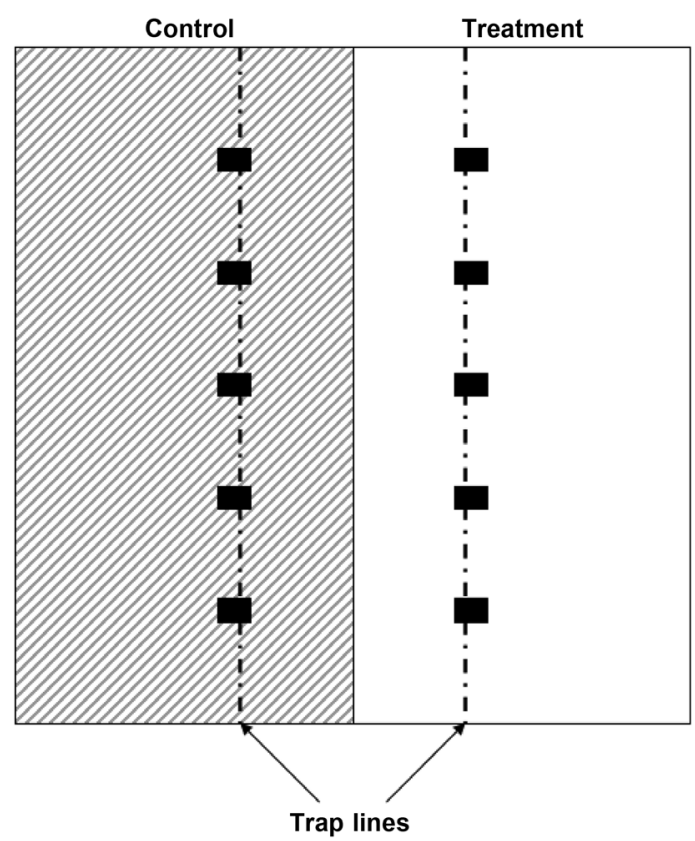

Fig. 1. Diagram of one experimental plot, with traps represented by black rectangles. There were five plots within the experiment, each containing ten Longworth traps, therefore 50 traps in total; 25 in the treatment and 25 in the control halves.

baited and armed at 10:00 the morning following cutting (ca. $20 \mathrm{~h}$ after cutting). Traps were then checked at five hourly intervals over the next 24 hours, as before. Following this trapping session, traps were again emptied, locked and left in place.

Session 3: four days after cutting. This session was run as session 2 and was started $48 \mathrm{~h}$ later, to see if there was a change in the pattern of small mammal captures with time after treatment. After the final trap round at 06:00, the traps were lifted before baling of the cut grass which took place the following day. Traps were then replaced and covered with a small amount of cut grass, and left empty and disarmed.

Session 4: $24 \mathrm{~h}$ after removal of cut grass. A final trapping session was carried out, commencing at 10:00 on the morning following the removal of the cut grass, to see if the removal of the vegetation had any effect on captures (Fig. 2).

To decouple the potentially confounding 


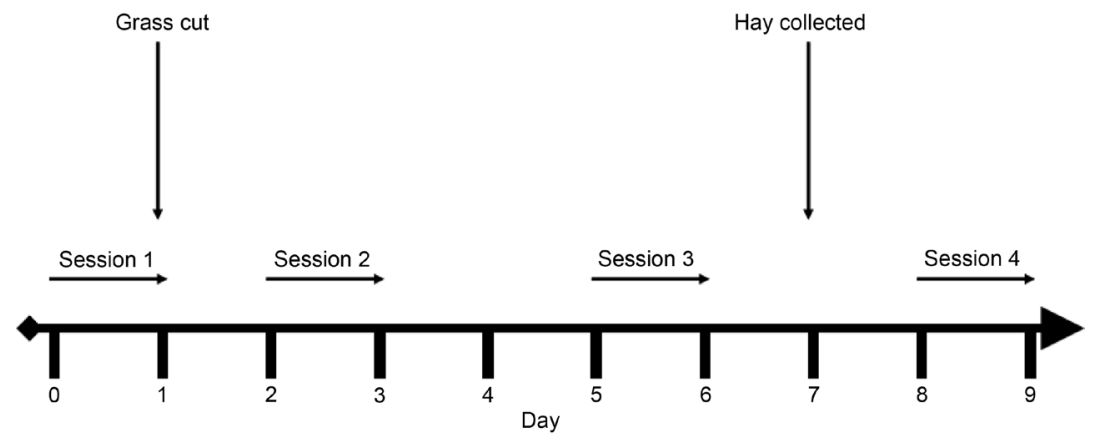

Fig. 2. Timeline of the experiment, with day zero being the first day on which trapping (session 1) commenced. Models 2, 3 and 4 presented in the results model the changes in capture probabilities between sessions 1 and 2 at days 0 and 2, sessions 2 and 3 at days 2 and 5 , and sessions 3 and 4 at days 5 and 8 .

effects of treatment and time, the cut grass was immediately collected prior to session 2 in one plot (no. 4), rather than left in situ. Unfortunately there was insufficient data to test the effects of session using this plot alone, and therefore data from this plot were not used in analyses of the post-cutting stages.

\section{Statistical analysis}

We ran the models using data from all of the trap rounds, and on a subset of the data using only the data from the 06:00 trap rounds. The latter approach reduced pseudoreplication in the trapping data (i.e. an individual in one trap could not be the same individual in another trap within the same trapping round), as the time schedule of the experiment did not allow for individual marking. We used the data from the 06:00 trapping round from each session of the experiment, because this was the time of day with the largest number of captures across the period of the whole experiment.

We used Generalised Linear Mixed Models (GLMMs) to model small mammal presence (probability of capture), with a binomial error structure and a logit link function. Plot was included in all models as a random effect, and treatment (i.e. cut or not cut, hay removed or not removed) and trapping session (see above and Fig. 2) were both included as fixed factors. Where appropriate, models included an interaction term between treatment and session, which tests whether the difference in capture probabil- ity between treatment and control plots is different between the sessions.

Because we set out to test a number of discrete a priori hypotheses, we ran separate models on the subsets of our data, detailed below. All models bar Model 1 (which only models session 1) are pairwise comparisons of each session with the next consecutive session, including an interaction term for treatment and session.

Model 1: Tests the hypothesis that there is no difference between the probability of capturing small mammals in control and treatment patches prior to grass cutting. This model included data from the first trapping session (pre-cutting) and all five experimental plots were used.

Model 2: Tests the hypothesis that there is no effect of grass cutting on the capture probability of small mammals. This model included data from session 1 (pre-cutting) and session 2 (post-cutting) and excluded plot 4 (see above). Cut grass was left in situ in all of the four plots included in the analysis.

Model 3: Tests the hypothesis that there is no difference in capture probability of small mammals $24 \mathrm{~h}$ and $96 \mathrm{~h}$ after cutting. This model included data from session 2 ( $24 \mathrm{~h}$ post-cutting) and session 3 (96 h post-cutting) and excluded plot 4 (see above). Cut grass was left in situ in all four plots included in this model.

Model 4: Tests the hypothesis that there is no effect of the removal of cut grass cover on the probability of capturing small mammals 
in the treatment plots. This model included data from session 3 (post-cutting, cut grass left in situ) and session 4 (post-cutting, cut grass removed) and excluded plot 4 .

All analyses were performed using $\mathrm{R}$ (version 2.9.1) ( $\mathrm{R}$ Development Core Team 2009) and the package lme4 v.0.99875.9 (Bates et al. 2008). We present the parameter estimate $(b)$ $\pm 1 \mathrm{SE}$ and the test statistic $(z)$ in the results, and for all tests a significance level of 0.05 was used.

\section{Results}

Across all trapping rounds, sessions and in both treatment and control plots, we caught a total number of six small mammal species represented by 264 individuals (see Appendix). The numbers trapped in the 06:00 periods across the experiment (i.e. data used in the statistical modelling presented below) were as follows: common shrew $(n=65)$, field vole $(n=6)$, wood mouse Apodemus sylvaticus $(n=3)$, pygmy shrew Sorex minutus $(n=1)$, bank vole $(n=1)$, and water shrew Neomys fodiens $(n=1)$. Apart from one bank vole, all of the 6 am captures in the treatment plots post-treatment were common shrews (Appendix). Before grass cutting, 30\% $(n=3)$ of small mammals were captured in control and $70 \%(n=7)$ in treatment patches. However, once the grass was cut only $27 \%(n=$ 4) of captures were in the treatment patches. This proportion decreased by ca. $25 \% 48$ hours later with $20 \%(n=3)$ caught in the cut grass. Upon removal of the grass, this proportion decreased a further $70 \%$, to only $6 \%(n=1)$ (Table 1$)$.

The results of the analysis of the entire data set (i.e. including all trapping sessions) were similar to results for the analysis of the 06:00 subset, only more strongly significant. Therefore, to reduce possible issues of pseudoreplication due to the animals not being marked, we report the results of the more conservative subset analysis here.

\section{Model 1}

There was no significant difference in the probability of capture between control and treatment plots before grass cutting $(b<0.001 \pm 0.611$, $z<0.001, p=0.999)$. This result did not change when plot 4 was excluded from the model $(b=$ $1.115 \pm 0.782, z=1.426, p=0.154)$.

\section{Model 2}

The interaction term between treatment and session was significant $(b=-2.821 \pm 1.08, z=$ $-2.614, p=0.009)$. This indicates that grass cutting affects the probability of capturing small mammals: this probability increased between sessions one and two in the control patches, but the opposite occurred in treatment (cut grass) patches (Fig. 3a).

\section{Model 3}

There was no significant effect of the interaction term between treatment and session $(b=-0.587$ $\pm 1.083, z=-0.542, p=0.588)$, thus there was no difference in the probability of capturing small mammals in the treatment plots between the two sessions following grass cutting, but prior to removal of the cut grass. Removal of

Table 1. Table showing the distribution of the 06:00 small mammal captures between control and treatment plots across all sessions of the experiment, and for replicates 1, 2, 3 and 5 only. The proportion of captures from treatment plots decreased by $61 \%$ between sessions 1 and 2, by $25 \%$ between sessions 2 and 3 , and by $70 \%$ between sessions 3 and 4 .

\begin{tabular}{lccccr}
\hline & Session 1 & Session 2 & Session 3 & Session 4 & Total \\
\hline Control & $3(30 \%)$ & $11(73 \%)$ & $12(80 \%)$ & $16(94 \%)$ & 42 \\
Treatment & $7(70 \%)$ & $4(27 \%)$ & $3(20 \%)$ & $1(6 \%)$ & 15 \\
Total & 10 & 15 & 15 & 17 & 57 \\
\hline
\end{tabular}




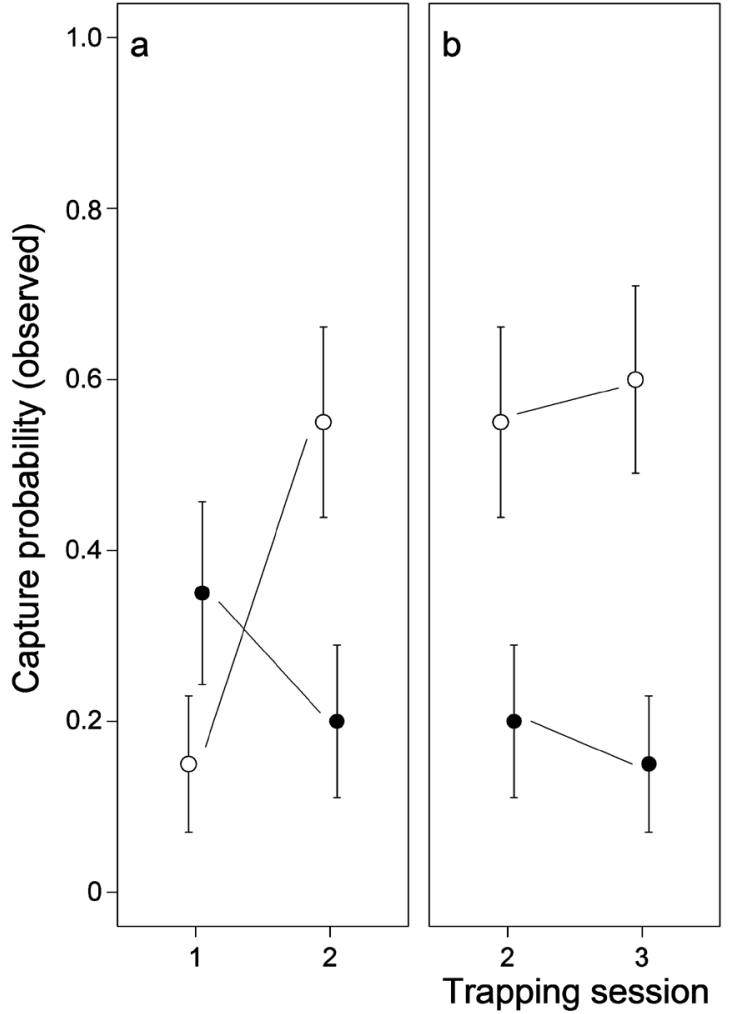

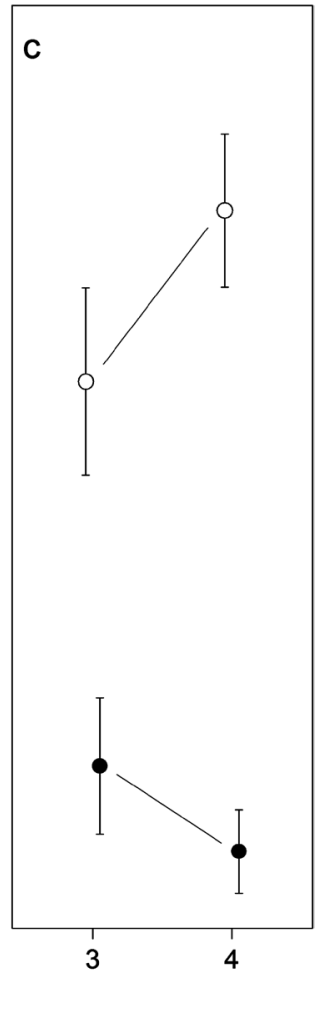

Fig. 3. Observed mean capture probabilities in treatment (filled circles) and control (open circles) patches (a) before and $24 \mathrm{~h}$ after cutting (sessions 1-2, model 2), (b) $24 \mathrm{~h}$ and $96 \mathrm{~h}$ after cutting (sessions 2-3, model 3), and (c) before and after removal of the cut grass (sessions 3-4, model 4). Error bars represent $\pm 1 \mathrm{SE}$. the interaction term showed that there was a significantly greater probability of capture in the uncut grass than the cut grass treatment $(b=$ $-1.985 \pm 0.542, z=-3.664, p<0.001)$. However, the probability of capturing small mammals did not change significantly with time/session $(b<$ $-0.001 \pm 0.52, z \sim 0, p>0.999$ ) (Fig. 3b).

\section{Model 4}

There was no significant effect of the interaction term between treatment (cut or not cut) and session (cut grass in situ or removed) $(b=-2.257$ $\pm 1.437, z=-1.570, p=0.116$ ). Although there was no significant change in the probability of capturing small mammals in the treatment plots between the two sessions, the probability of capture tended to decrease in the treatment patches, and increased in the control patches (Fig. 3c). Removal of the interaction term showed that there was a significantly greater probability of capture in the uncut grass than the cut grass treatment $(b=-3.175 \pm 0.649, z=-4.895, p<0.001)$.
However, the probability of capturing small mammals did not change significantly with session (i.e. presence or absence of cut grass cover; $b=0.346 \pm 0.59, z=0.586, p=0.558)$.

\section{Discussion}

Our results show that grass cutting significantly affects the probability of capturing small mammals, as demonstrated by the change in capture probabilities in cut and uncut areas. These results are significant even though data have only been used from one of four trap rounds carried out at each stage of the experiment (06:00), thereby reducing issues of pseudoreplication. Our findings support the suggestion from previous work (e.g. Edge et al. 1995, Jacob 2003, Jacob \& Hempel 2003) that grass cutting causes rapid movement of small mammals out of the cut areas, but that a small proportion will remain in these cut areas.

Cutting grass on farmland may therefore be a good management strategy to aid raptors, by 
increasing visibility of their prey. Kestrels hunt by sight, and thick vegetative cover is almost certainly disadvantageous for them. Additionally, the urine and faeces trails left by small mammals to mark their runways are visible in ultraviolet light, which appears to be detectable by some diurnal birds of prey (Viitala et al. 1995, Koivula \& Viitala 1999). This potentially allows foraging raptors to rapidly assess an area for small mammal abundance and thereby assess the profitability of a particular hunting patch, provided the grass is short enough to see the trails (Viitala et al. 1995, Koivula \& Viitala 1999). It would seem likely that it also makes any small mammals remaining in the area easier to actually catch.

As discussed above, the non-zero capture probabilities following treatment show that some small mammals are found in patches of freshly cut grass (at least for eight to nine days following cutting). Due to our study design, we cannot distinguish between individuals that stayed in the treatment patches, and individuals that returned or moved into the area from outside. This is important, because the presence of baited traps per se could explain the latter pattern. However, even if this is the case, it suggests that some small mammals will continue to use an area of cut grass provided it still contains a required resource (e.g. food) or due to territorial pressures on dispersal, as optimal unmown habitats surrounding the mown areas are likely to resist immigrants if already saturated (Hansson 1977). This suggestion is further supported by Jacob and Hempel (2003), who found that radio-collared common voles Microtus arvalis Pallas did not leave their territories even after substantial habitat alteration by mowing.

Furthermore, we found that removing the cut grass tended to decrease capture probabilities even further. Although not significant, the pattern of capture probabilities between sessions 3 and 4 is strongly suggestive of an increased effect of treatment. This suggestion is reinforced by the change in proportion of captures in treatment $v s$. control (Table 1 and Fig. 3c), which decreased from $20 \%$ in session 3 to just $6 \%$ in session 4 - a decrease of $70 \%$. Thus, our results further stress the importance of the presence of cover to small mammals (e.g. Birney et al. 1976, Hansson 1977, Hansson 1982, Ostfeld 1985, Pusenius
\& Viitala 1993). These findings strongly suggest that the majority of small mammals that continue to use a patch after grass cutting would no longer do so if all remaining cover (i.e. the cut grass) is also removed. We, therefore, suggest that grass cutting per se is not as important a determinant of the effect of mowing on small mammals, as whether the cut grass is left in situ.

Almost all of the captures in treatment patches post-cutting were common shrews. Shrews have high energy demands and need to eat every few hours to survive (Barnard \& Brown 1984). Thus, shrews may not respond to rapid changes in habitat suitability as quickly as other small mammal species. Combined with their high relative abundance and high daytime activity rates, this makes them disproportionately vulnerable to predation in altered habitats (e.g. due to grass cutting) and an important food source for birds of prey.

It is important to note that the results presented should not be extrapolated to encourage the cutting of large areas of grass simultaneously. Instead leaving patches of taller grass or other habitat (e.g. woodland or hedgerows) to create conditions for the long-term survival of small mammal populations is likely to be useful for maintaining healthy mammal populations on farmland. Bank voles are most commonly found in hedges in agricultural areas, and along with wood mice are very abundant in this habitat. Conversely, field voles prefer grass-dominated habitats at field boundaries, therefore increasing the area of both these habitats should in theory increase small mammal abundance and diversity on farmland (Butet et al. 2006).

The current study provides evidence that not all small mammals leave areas of grass that have been cut. This suggests that as long as some form of cover is provided (e.g. the cut grass), mowing can be considered a management tool that is likely to improve access to preferred prey of several diurnal raptor species, some of which continue to decline in the UK and elsewhere in Europe.

\section{Acknowledgements}

Firstly, and most importantly, thanks to Durham Wildlife 
Trust at Rainton Meadows, for generously allowing us to use their nature reserve as an experimental site, their volunteer room as a camp site, and their staff (Jim Cokill, Mark Richardson, Mark Dinning and Lisa Givens) as volunteers. Also, thanks to Ben Brilot, Lizzie Ross, Mo Quinn, Emma White, Sarah Cotterill and Trevor Wright for volunteering to help with the surveys in difficult terrain, unsociable hours, and with little sleep. Thanks also to the Northumbria Mammal group, particularly Veronica Carnell, for training in the principles of live trapping small mammals, and thanks to Durham University for the loan of Longworth traps. This study was funded by Natural England.

\section{References}

Aebischer, N. J., Green, R. E. \& Evans, A. D. 2000: From science to recovery: four case studies of how research has been translated into conservation action in the UK. - In: Aebischer, N. J., Evans, A. D., Grice, P. V. \& Vickery, J. A. (eds.), Ecology and conservation of lowland farmland birds: 43-54. British Ornithologists' Union, Tring.

Albrecht, M., Duelli, P., Müller, C., Kleijn, D. \& Schmid, B. 2007: The Swiss agri-environment scheme enhances pollinator diversity and plant reproductive success in nearby intensively managed farmland. - Journal of Applied Ecology 44: 813-822.

Aschwanden, J., Birrer, S. \& Jenni, L. 2005: Are ecological compensation areas attractive hunting sites for common kestrels (Falco tinnunculus) and long-eared owls (Asio otus)? - Journal of Ornithology 146: 279-286.

Aschwanden, J., Holzgang, O. \& Jenni, L. 2007: Importance of ecological compensation areas for small mammals in intensively farmed areas. - Wildlife Biology 13: $150-158$.

Baker, J. A. \& Brooks, R. J. 1981: Distribution patterns of raptors in relation to density of meadow voles. - The Condor 83: 42-47.

Barnard, C. J. \& Brown, C. A. J. 1985: Risk-sensitive foraging in common shrews (Sorex araneus L.). - Behavioral Ecology and Sociobiology 16: 161-164.

Bates, D., Maechler, M. \& Dai, B. 2008: Lme4: Linear mixed-effects models using $S 4$ classes. $R$ package version 0.999375-28. - Available at http://lme4.r-forge.rproject.org/.

Bellamy, P. E., Shore, R. F., Ardeshir, D., Treweek, J. R. \& Sparks, T. H. 2000: Road verges as habitat for small mammals in Britain. - Mammal Review 30: 131-139.

Birney, E. C., Grant, W. E. \& Baird, D. D. 1976: Importance of vegetative cover to cycles of Microtus populations. Ecology 57: 1043-1051.

Butet, A., Paillat, G. \& Delettre, Y. 2006: Seasonal changes in small mammal assemblages from field boundaries in an agricultural landscape of western France. - Agriculture, Ecosystems \& Environment 113: 364-369.

Cavé, A. J. 1968: The breeding of the kestrel, Falco tinnunculus L., in the reclaimed area Oostelijk Flevoland. Netherlands Journal of Zoology 18: 313-407.
Convention on Biological Diversity 2004: Addis Ababa principles and guidelines for the sustainable use of biodiversity. - Secretariat of the Convention on Biological Diversity, Montreal, Canada.

Churchfield, S., Hollieran, J. \& Brown, D. V. K. 1997: Community structure and habitat use of small mammals in grasslands of different successional age. - Journal of Zoology, London 242: 519-530.

Davey, C. M., Vickery, J. A., Boatman, N. D., Chamberlain, D. E., Parry, H. R. \& Siriwardena, G. M. 2010: Assessing the impact of Entry Level Stewardship on lowland farmland birds in England. - Ibis 152: 459-474.

Dickman, C. R. \& Doncaster, C. P. 1987: The ecology of small mammals in urban habitats. I. Populations in a patchy environment. - Journal of Animal Ecology 56: 629-640.

Edge, W. D., Wolff, J. O. \& Carey, R. L. 1995: Densitydependent responses of gray-tailed voles to mowing. Journal of Wildlife Management 59: 245-251.

Garratt, C. G., Hughes, M., Eagle, G., Fowler, T., Grice, P. V. \& Whittingham, M. J. 2011: Foraging habitat selection by breeding kestrels Falco tinnunculus on lowland farmland in England. - Bird Study 58: 90-98.

Glue, D. E. 1974: Food of the barn owl in Britain and Ireland. - Bird Study 21: 200-210.

Green, R. E., Cornell, S. J., Scharlemann, J. P. W. \& Balmford, A. 2005: Farming and the fate of wild nature. Science 307: 550-555.

Grice, P. V., Radley, G. P., Smallshire, D. \& Green, M. R. 2007: Conserving England's arable biodiversity through agri-environment schemes and other environmental policies: a brief history. - Aspects of Applied Biology 81: $7-22$.

Hansson, L. 1977: Spatial dynamics of field voles Microtus agrestis in heterogeneous landscapes. - Oikos 29: 539-544.

Hansson, L. 1982: Experiments on habitat selection in voles: Implications for the inverse distribution of two common European species. - Oecologia 52: 246-252.

Jacob, J. 2003: Short-term effects of farming practices on populations of common voles. - Agriculture, Ecosystem \& Environment 95: 321-325.

Jacob, J. \& Brown, J. S. 2000: Microhabitat use, giving-up densities and temporal activity as short- and long-term anti-predator behaviours in common voles. - Oikos 91: 131-138.

Jacob, J. \& Hempel, N. 2003: Effects of farming practices on spatial behaviour of common voles. - Journal of Ethology 21: 45-50.

Kikkawa, J. 1964: Movement, activity and distribution of the small rodents Clethrionomys glareolus and Apodemus sylvaticus in woodland. - Journal of Animal Ecology 33: 259-299.

Kleijn, D., Berendse, F., Smit, R. \& Gilissen, N. 2001: Agri-environment schemes do not effectively protect biodiversity in Dutch agricultural landscapes. - Nature 413: 723-725.

Kleijn, D., Berendse, F., Smit, R., Gilissen, N., Smit, J., Brak, B. \& Groeneveld, R. 2004: The ecological effectiveness of agri-environment schemes in different agricultural 
landscapes in the Netherlands. - Conservation Biology 18: 775-786.

Kleijn, D., Baquero, R. A., Clough, Y., Díaz, M., De Esteban, J., Fernández, F., Gabriel, D., Herzog, F., Holzschuh, A., Jöhl, R., Knop, E., Kruess, A., Marshall, E. J. P., Steffan-Dewenter, I., Tscharntke, T., Verhulst, J., West, T. M. \& Yela, J. L. 2006: Mixed biodiversity benefits of agri-environment schemes in five European countries. - Ecology Letters 9: 243-254.

Koivula, M. \& Viitala, J. 1999: Rough-legged buzzards use vole scent marks to assess hunting areas. - Journal of Avian Biology 30: 329-332.

Koks, B. J., Trierweiler, C., Visser, E. G., Dijkstra, C. \& Komdeur, J. 2007: Do voles make agricultural habitat attractive to montagu's harrier Circus pygargus? - Ibis 149: 575-586.

Korpimäki, E. 1984: Population dynamics of birds of prey in relation to fluctuations in small mammal populations in western Finland. - Annales Zoologici Fennici 21: 287-293.

Korpimäki, E. \& Norrdahl, K. 1991: Numerical and functional responses of kestrels, short-eared owls, and longeared owls to vole densities. - Ecology 72: 814-826.

Lemen, C. A. \& Clausen, M. K. 1984: The effects of mowing on the rodent community of a native tall grass prairie in eastern Nebraska. - Prairie Naturalist 16: 5-10.

Meunier, F. D., Corbin, J., Verheyden, C. \& Jouventin, P. 1999: Effects of landscape type and extensive management on use of motorway roadsides by small mammals. - Canadian Journal of Zoology 77: 108-117.

Ostfeld, R. S. 1985: Limiting resources and territoriality in microtine rodents. - The American Naturalist 126: 1-15.

Ovenden, G. N., Swash, A. R. H. \& Smallshire, D. 1998: Agri-environment schemes and their contribution to the conservation of biodiversity in England. - Journal of Applied Ecology 35: 955-960.

Peach, W. J., Lovett, L. J., Wotton, S. R. \& Jeffs, C. 2001: Countryside stewardship delivers cirl buntings (Emberiza cirlus) in Devon, UK. - Biological Conservation 101: 361-373.

Perkins, A., Maggs, H., Watson, A. \& Wilson, J. 2011:
Adaptive management and targeting of agri-environment schemes does benefit biodiversity: a case study of the Corn Bunting Emberiza calandra. - Journal of Applied Ecology 48: 514-522.

Pusenius, J. \& Viitala, J. 1993: Demography and regulation of breeding density in the field vole Microtus agrestis. - Annales Zoologici Fennici 30: 133-142.

$\mathrm{R}$ Development Core Team 2009: $R$ : A language and environment for statistical computing. - $\mathrm{R}$ Foundation for Statistical Computing, Vienna, Austria, also available at http://www.R-project.org.

Redpath, S. M. \& Thirgood, S. J. 1999: Numerical and functional responses in generalist predators: hen harriers and peregrines on Scottish grouse moors. - Journal of Animal Ecology 68: 879-892.

Risely, K., Baillie, S. R., Eaton, M. A., Joys, A. C., Musgrove, A. J., Noble, D. G., Renwick, A. R. \& Wright, L. J. 2010: The Breeding Bird Survey 2009. - BTO Research Report 559, British Trust for Ornithology, Thetford.

Sheffield, L. M., Crait, J. R., Edge, D. W. \& Wang, G. 2001: Response of American kestrels and gray-tailed voles to vegetation height and supplemental perches. - Canadian Journal of Zoology 79: 380-385.

Shore, R. F., Meek, W. R., Sparks, T. H., Pywell, R. F. \& Nowakowski, M. 2005: Will Environmental Stewardship enhance small mammal abundance on intensively managed farmland? - Mammal Review 35: 277-284.

Tattersall, F. H., Avundo, A. E., Manley, W. J., Hart, B. J. \& Macdonald, D. W. 2000: Managing set-aside for field voles (Microtus agrestis). - Biological Conservation 96: $123-128$.

Viitala, J., Korpimäki, E., Palokangas, P. \& Kolvula, M. 1995: Attraction of kestrels to vole scent marks visible in ultraviolet light. - Nature 373: 425-427.

Village, A. 1990: The Kestrel. - Poyser, London.

Whittingham, M. J. 2007: Will agri-environment schemes deliver substantial biodiversity gain, and if not why not? - Journal of Applied Ecology 44: 1-5.

Whittingham, M. J. \& Devereux, C. L. 2008: Changing grass height alters foraging site selection by wintering farmland birds. - Basic and Applied Ecology 9: 779-788. 
Appendix. Tables showing the total captures of each of the six species of small mammals caught, across all sessions of the experiment, for all five replicates and for each of the four trap rounds carried out during each session. Captures from replicates 1, 2, 3 and 5, and from the 06:00 trap rounds only were used in the statistical analysis of the results.

\begin{tabular}{|c|c|c|c|c|c|c|c|c|c|}
\hline \multirow[b]{2}{*}{ Replicate \& species } & \multicolumn{2}{|c|}{$15: 00$} & \multicolumn{2}{|c|}{$20: 00$} & \multicolumn{2}{|c|}{ 01:00 } & \multicolumn{2}{|c|}{ 06:00 } & \multirow[t]{2}{*}{ Total } \\
\hline & Treatment & Control & Treatment & Control & Treatment & Control & Treatment & Control & \\
\hline
\end{tabular}

\section{Session 1}

1 S. araneus

S. minutus

2 S. araneus

M. agrestis

M. glareolus

A. sylvaticus

3 S. araneus

$M$. agrestis

M. glareolus

$S$. minutus

4 S. araneus

M. glareolus

5 S. araneus

S. minutus

Total

\section{Session 2}

1 S. araneus

S. minutus

2 S. araneus

M. agrestis

3 S. araneus

M. glareolus

A. sylvaticus

S. minutus

4 S. araneus

M. agrestis

5 S. araneus

M. agrestis

A. sylvaticus

Total

\section{Session 3}

1 S. araneus

2 S. araneus

M. agrestis

3 S. araneus

M. glareolus

4 S. araneus

M. agrestis

5 S. araneus

S. minutus

Total

\section{Session 4}

1 S. araneus

2 S. araneus

M. agrestis

$N$. fodiens

3 S. araneus

4 S. araneus

M. agrestis

5 S. araneus

Total

\section{5}

1

$$
1
$$

2

$2 \quad 1$

1

8

